九州大学学術情報リポジトリ

Kyushu University Institutional Repository

Evaluation of the Edge-effect on the Farmland Production Environment in Hilly and Mountainous Areas (2) : Energy Balance on the Soil Surface

Yuge, Kozue

Faculty of Agriculture, Kyushu University

Baba, Chinami

Taiyo Consultants Co.

Anan, Mitsumasa

Graduate School of Bioresource and Bioenvironmental Sciences, Kyushu University

Nakano, Yoshisuke

Faculty of Agriculture, Kyushu University

https://doi.org/10.5109/9301

出版情報: 九州大学大学院農学研究院紀要. 52 (1)，pp.171-174，2007-02-28. Faculty of Agriculture, Kyushu University

バージョン：

権利関係 : 


\title{
Evaluation of the Edge-effect on the Farmland Production Environment in Hilly and Mountainous Areas (2)-Energy Balance on the Soil Surface
}

\author{
Kozue YUGE*, Chinami Baba ${ }^{1}$, Mitsumasa ANAN $^{2}$ \\ and Yoshisuke NAKANO
}

\author{
Laboratory of Irrigation and Water Utilization, Division of Regional Environment Science, Department of \\ Bioproduction Environmental Sciences, Faculty of Agriculture, \\ Kyushu University, Fukuoka 812-8581, Japan \\ (Received November 10, 2006 and accepted December 1, 2006)
}

\begin{abstract}
The objectives of this study are evaluating the energy balance and water consumption on the soil surface of the farmland located in the hilly and mountainous areas, considering the effect of the shelter adjacent to the farmland, such as the forest (This effect is called as the edge-effect in this study.). Field experiment is conducted at the observational field arranged to imitate the actual farmland adjacent to the forest. The solar radiation and temperature on the soil surface are measured at the 4 measurement points, and the spatial and temporal changes of the energy balance components, including the net radiation, sensible heat flux, ground heat flux, are quantified using the measurement data. The net radiation and the latent heat flux show the large spatial variations, comparing with the sensible heat flux and ground heat flux. At the point facing the north and in the vicinity of shelter, the condensation is obtained. The results indicated that the shelter adjacent to the farmland in the hilly and mountainous areas brings the spatial variation of the energy balance and water consumption on the field surface.
\end{abstract}

\section{INTRODUCTION}

In Japan, most of the farmland is located in the hilly and mountainous areas. One of the most important micrometeorological factors for agricultural production is solar radiation, because it affects the water consumption and the thermal environment in the farmland. The solar radiation environment in the hilly and mountainous areas is very complicated because it is affected by shelter, such as the canopy of forest, adjacent to the field and the field surface orientation. This phenomenon brings the spatial variation of the energy balance components, including the sensible heat flux, ground heat flux, and latent heat flux. Particularly the latent heat flux is very important component in the viewpoint of the irrigation planning.

The solar radiation environment in the hilly and mountainous areas was quantified, considering the topographic feature, by Miura et al. (1980) and Nakano et al. (2005). These studies are effective for quantifying the solar radiation environment, considering the field surface orientation. However the energy balance, considering the shelter effect (This effect is called as the edge-effect in this study.), has not yet been clarified.

The objectives of this study are evaluating the energy balance and water consumption on the soil surface of the farmland adjacent to the forest. Field experiment is conducted at the observational field arranged to imitate the actual farmland adjacent to the forest. The spatial and temporal changes of the energy balance com-

1 Taiyo Consultants Co., Ltd

2 Laboratory of Irrigation and Water Utilization, Division of Regional Environment Science, Department of Bioproduction Environmental Sciences, Graduate School of Bioresource and Bioenvironmental Sciences, Kyushu University

* Corresponding author (E-mail: yuge@bpes.kyushu-u.ac.jp) ponents are quantified experimentally.

\section{ENERGY BALANCE ON THE BARE SOIL SURFACE}

The energy balance on the bare soil surface can be described as follows:

$$
R_{\text {net }}=l E+H+G
$$

where $E$ is the latent heat flux, $G$ is the ground heat flux, $H$ is the sensible heat flux, $R_{\text {net }}$ is the net radiation, and $l$ is the latent heat of the water vaporization.

$R_{\text {net }}$ on the bare soil surface can be estimated as follows:

$$
R_{\text {net }}=R_{s}+L \downarrow-L \uparrow
$$

where $R_{s}$ is the shortwave(solar) radiation, $L \downarrow$ is the longwave radiation from the sky, and $L \uparrow$ is the longwave radiation from the soil surface.

$L \downarrow$ and $L \uparrow$ can be calculated using the following equations, respectively.

$$
\begin{aligned}
& L \downarrow=\left(0.53+0.066 \sqrt{e_{a}}\right) \sigma T_{a}^{4} \\
& L \uparrow=\epsilon \sigma T_{s}^{4}
\end{aligned}
$$

where $T_{a}$ is the air temperature, $T_{s}$ is the soil surface temperature, $e_{a}$ is the vapor pressure of the air, and $\sigma$ is the Stefan-Boltzmann Constant.

$l E$ and $H$ can be estimated by following equations.

$$
\begin{aligned}
& l E=\frac{\rho C_{P}}{\mathrm{Y}} \frac{e_{s}-e_{a}}{r_{a}} \\
& H=\rho C_{P} \frac{T_{s}-T_{a}}{r_{a}}
\end{aligned}
$$


where $C_{p}$ is the specific heat of air, $e_{s}$ is the vapor pressure on the soil surface, $r_{a}$ is the diffusion resistance, $\mathrm{Y}$ is the psychrometer constant, and $\rho$ is the air density.

Under the neutral condition, $r_{a}$ can be estimated as follows:

$$
r_{a}=\frac{1}{\kappa u_{*}} \ln \left(\frac{z}{z_{0}}\right)+a\left(\frac{u_{*} \zeta}{v}\right)^{b}\left(\frac{v}{D_{v}}\right)^{c}
$$

where $D_{v}$ is the molecular diffusion coefficient, $u_{*}$ is the friction velocity, $z$ is the height of the measurement of the wind velocity, $z_{0}$ is the roughness length, $\zeta$ is the effective soil surface roughness, and $v$ is the kinematic viscosity of air. The constants $a, b$, and $c$ are reported as $0.52,0.45$, and 0.8 , respectively, by Chamberlain (1968).

Generally, the vapor pressure $e_{s}$ on the soil surface can be calculated as follows:

$$
e_{s}=6.1078\left(\frac{17.27 T_{s}}{T_{s}+237.3}\right) \exp \left(\frac{g \boldsymbol{\Psi}}{R_{w}\left(T_{s}+273.16\right)}\right)
$$

where $R_{w}$ is the gas constant of the vapor, $g$ is the gravity acceleration, and $\boldsymbol{\Psi}$ is the soil water potential on the soil surface when the air vapor pressure and the soil surface vapor pressure are balanced. In an actual field, estimating the vapor pressure on the soil surface and the latent heat flux is difficult using eq. (5). The latent heat flux is calculated by following equation in this study.

$$
l E=R_{\text {net }}-(H+G)
$$

The ground heat flux $G$ can be estimated as follows:

$$
G=-\lambda \frac{\partial T_{s}}{\partial z}
$$

where $\lambda$ is the soil thermal conductivity.

\section{FIELD OBSERVATION}

Figure 1 shows the observational field set at the Kyushu Univ. The shelter, describing the forest adjacent to the actual farmland in the hilly and mountainous areas is set at the center of the terrace field. The field observation conducted on 27th Jan. 2006. The solar radiations are measured at 4 measurement points shown in Fig. 1 using the pyranometers (LI-COR, LI-200) every 10 minute. The soil temperatures at the depth of $0 \mathrm{~m}$ and $0.025 \mathrm{~m}$ are measured at 4 points shown in Fig. 1

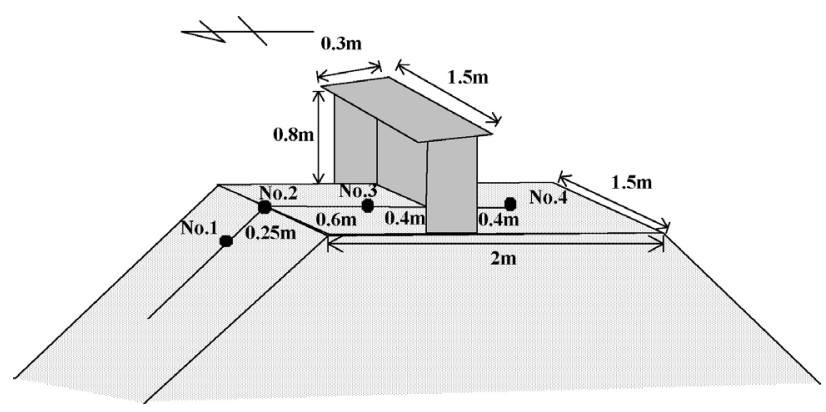

Fig. 1. Observational field. by thermocouples every 10 minute. Wind velocity, air temperature and humidity are measured at the observational field every 10 minute.

\section{RESULTS AND DISCUSSION}

Figure 2 shows the solar radiation measured at 4 measurement points shown in Fig. 1. The solar radiation at No. 1 is large, comparing with other measurement points at the part facing the north. At No. 3, the solar irradiance is very small during the daytime. This figure indicates that the solar radiation environment at the part facing the north is affected the shelters. Figure 3 shows the spatial distributions of the soil surface temperature at the north part measured every 3 hour by the infrared thermal imaging camera (NEC San-ei, TH7102). As shown in this figure, the soil surface temperature changes temporally and spatially, affected by the shelter shadow. The result indicates that the spatial and temporal variations of the solar radiation environment, as shown in Fig. 1, affect the thermal condition on the soil surface.

Using these results, the net radiations at 4 measurement points are estimated by eq. (2) as shown in Fig. 4.

The sensible heat fluxes at 4 points estimated by eq. (6) are shown in Fig. 5. The sensible heat flux at the part facing the south is large, and the value of the sensible heat fluxes shows minus at No. 1, No. 2 and No. 3. Figure 6 shows the ground heat fluxes calculated by eq. (10). The ground heat flux at No. 4 is larger, and the relative large value can be obtained at No. 3. There is no difference of the ground heat flux between No. 1 and No. 2.

Figure 7 shows the latent heat flux estimated by eq. (9). This figure indicated that the latent heat fluxes show the spatial change affected by the shelters. At No. 4 , the latent heat flux is large during the daytime and decreases abruptly around the 4 P.M. The latent heat flux at No.1 is relatively large, and around 4 P.M., the gradual decrease of the latent heat flux is obtained. The change of the latent heat flux at No. 2 is similar to the change of No. 1. At No. 3, the latent heat flux shows the minus values during all day. This result indicates that the vapor is transferred from the air to the soil on the surface. The daily soil surface evaporation estimated by

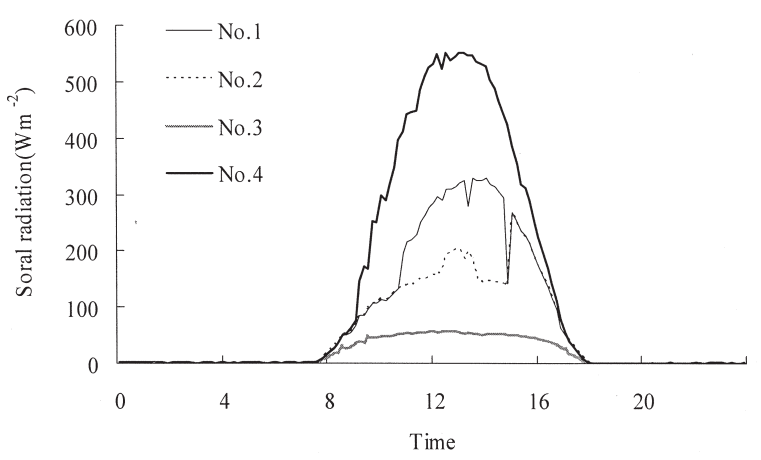

Fig. 2. Diurnal changes of the solar radiation. 

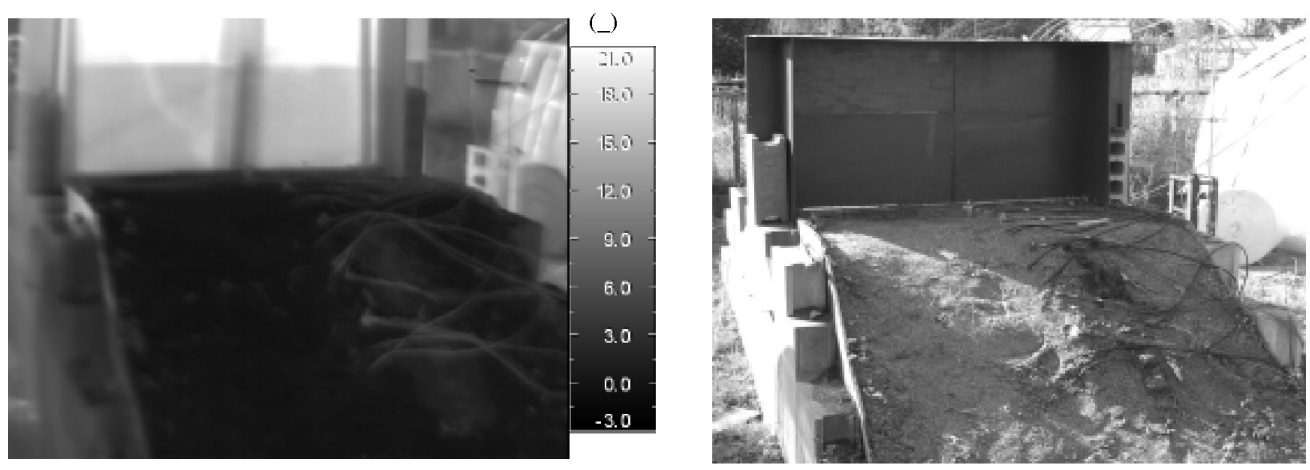

(a) 9:00
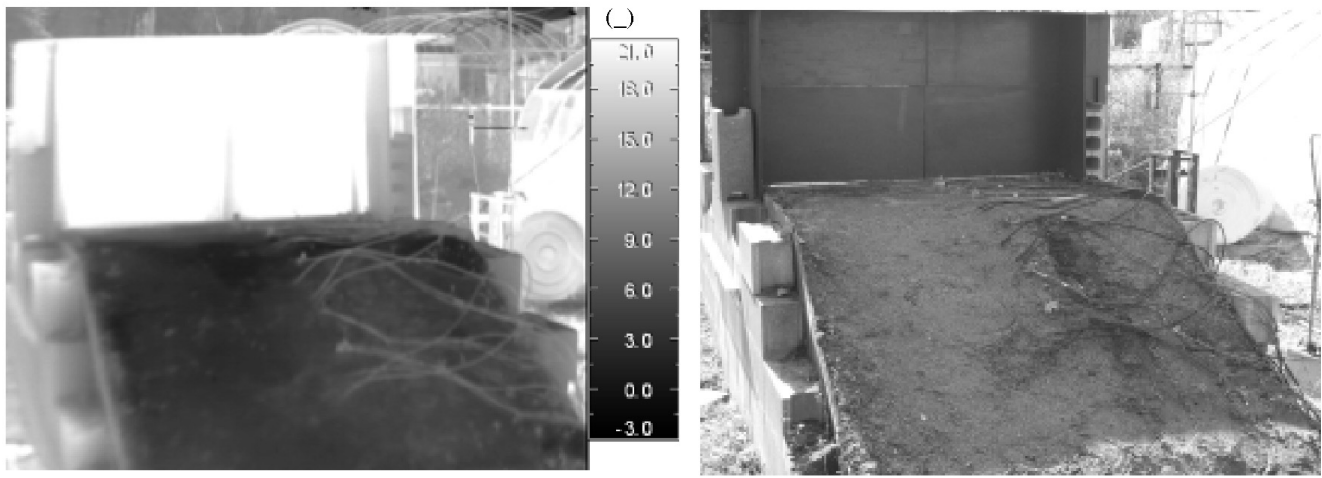

(b) 12:00
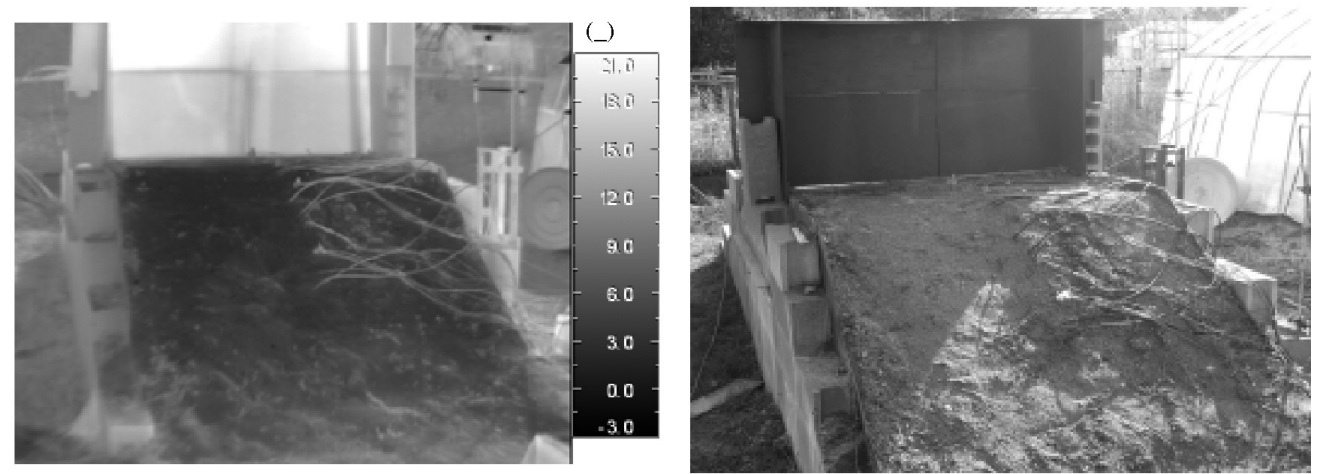

(c) $15: 00$

Fig. 3. Spatial distribution of the soil surface temperature.

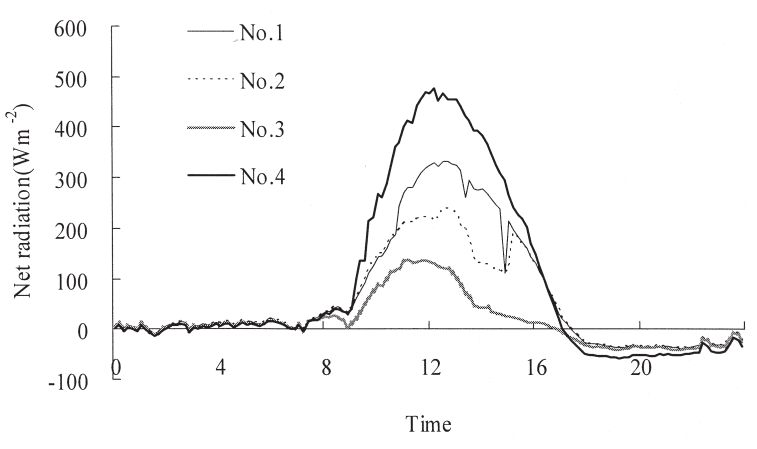

Fig. 4. Diurnal changes of the net radiation.

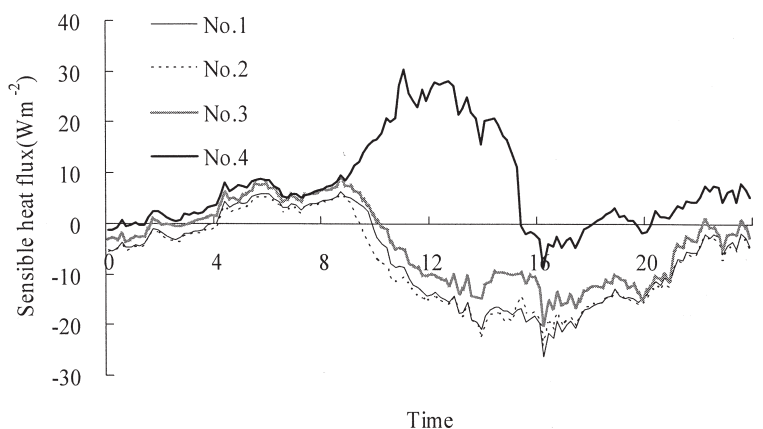

Fig. 5. Diurnal changes of the sensible heat flux. 


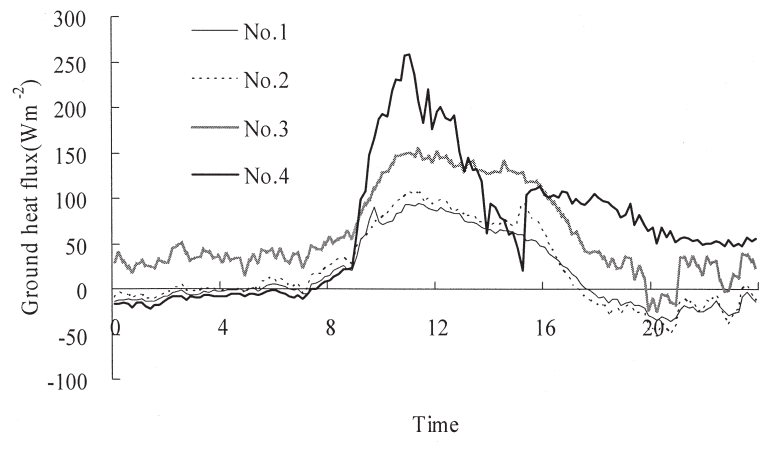

Fig. 6. Diurnal changes of the ground heat flux.

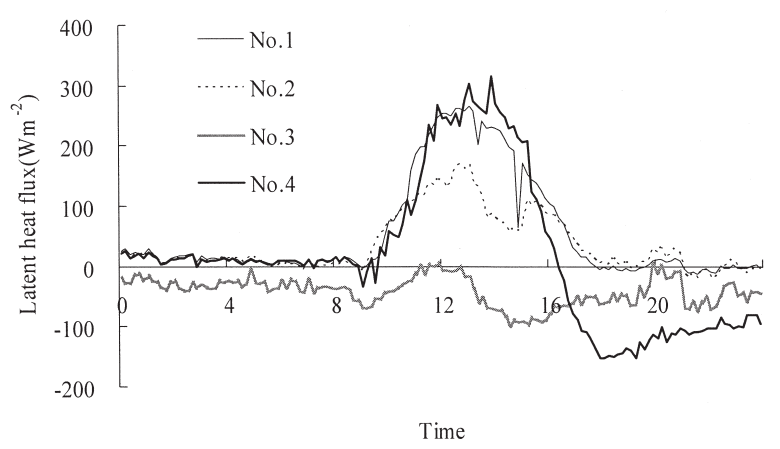

Fig. 7. Diurnal changes of the latent heat flux.

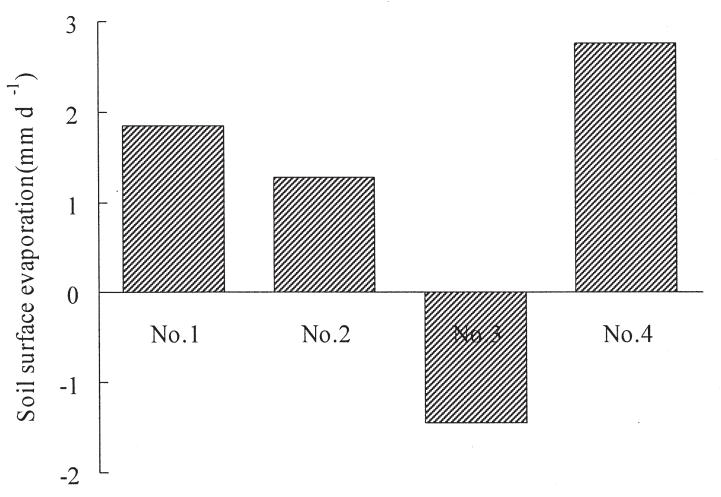

Fig. 8. Daily soil surface evaporation. value of the temporal latent heat flux is shown in Fig. 8. This figure indicates that the amounts of water consumption vary spatially because of the edge-effect. The water consumption at No. 4 is large, comparing with another measurement points. At No. 3, the condensation is obtained.

\section{CONCLUSIONS}

To evaluate the edge-effect on the energy balance in the hilly and mountainous areas, the field observation is conducted. The observational field is arranged using a shelter to imitate the actual farmland adjacent to the forest. First, the solar radiation is observed at 4 measurement points. The solar radiation shows spatial difference affected by the shelters. Using the solar radiation measurement, the energy balance components, including the net radiation, sensible heat flux, ground heat flux, and latent heat fluxes are estimated. The net radiation and the latent heat flux show the large spatial differences, comparing with the sensible heat flux and ground heat flux. Particularly, the spatial variation of the latent heat flux is noticeable. At the point facing the north and in the vicinity of shelter, the condensation is obtained. The results indicated that the shelter adjacent to the farmland in the hilly and mountainous areas brings the spatial variation of the energy balance on the field surface. Particularly, the spatial change of the water consumption in the field adjacent to the shelter is considerable. The complicated energy environment should be taken into account for planning irrigation and planting.

\section{REFERENCES}

Chamberlain, A. C. 1968 Transport of gases to and from surface with bluff and wave-like roughness elements. Q. J. Roy. Met. Soc. 94: 318-332.

Miura T., T. Mitsuno, T. Maruyama and A. Yomota 1980 Calculation method of the distribution of the amount of insolation in mountainous areas-Studies on the mechanism of the thermal environment formation in mountainous area (1)-. Trans. JSIDRE, 88: 1-7(in Japanese)

Nakano Y., K. Yuge, T. Haraguchi, A. Marui, S. K. Saptomo and A. Hao 2005 Evaluation of the intrinsic environment changes resulted from the farmland consolidation in a hilled area. $J$. Agri. Meteorol., 60 (5): 713-716 